Tree Swallows will re-lay upon the loss of their first clutch, and about one third (29\%) of those that relay will lay a second replacement (i.e., third) clutch. Although the ability to re-lay is likely molded by natural selection and influenced by many factors, such as adult survivorship, length of breeding season, food abundance, and frequency of nest loss, further study will be required to determine the decision rules used by females in deciding whether or not to re-lay.

We thank Steve Hermans, Colleen Barber, Mark Hovorka, Jeff Dawson, Paul Martin, Karen Willson, and Clive Goodinson for their help in the field. Colleen Barber and Dorothy Hill provided constructive comments on earlier drafts of the manuscript. This research was supported by an NSERC grant to RJR.

\section{LITERATURE CITED}

Askenmo, C, 1979. Reproductive effort and return rate of male Pied Flycatchers. Am. Nat. 114:748-753.

Bryant, D. M. 1979. Reproductive costs in the House Martin (Delichon urbica). J. Anim. Ecol. 48:655-675.

Chapman, L. B. 1955. Studies of a Tree Swallow colony. Bird-Banding 26:45-70.

Gill, F., AND A. PoOle [ens]. 1992-1996. The birds of North America. No. 1-208. The Academy of Natural Sciences, Philadelphia, and The American Ornithologists' Union, Washington, DC.

Hussell, D. J. T. 1972. Factors affecting clutch size in arctic passerines. Ecol. Monogr. 42:317-364.
Hussell, D. J. T. 1983. Tree Swallow pairs raise two broods per season. Wilson Bull. 95:470-471.

Lombardo, M. P. 1983. Female Tree Swallow lays three clutches during one breeding season. Wilson Bull. 95:146.

Mitchell, J. S., and R. J. Robertson. 1993. Tree Swallows cannot be classified as determinate or indeterminate layers. Condor 95:546-553.

Nur, N. 1986. Is clutch size variation in the Blue Tit (Parus caeruleus) adaptive? An experimental study. J. Anim. Ecol. 55:983-999.

Nur, N. 1987. Alternative reproductive tactics in birds: individual variation in clutch size, p. 4977. In P. P. G. Bateson and P. H. Klopfer [eds.], Perspectives in ethology, Vol. 7. Plenum Press, New York.

Perrins, C. M. 1970. The timing of birds' breeding seasons. Ibis 112:242-255.

Robertson, R. J., B. J. Stutchbury, and R. R. Cohen. 1992. Tree Swallow (Tachycineta bicolor), $\mathrm{p}$. 13-15. In A. Poole and F. Gill [eds.], The birds of North America, No. 11. The Academy of Natural Sciences, Philadelphia, and The American Ornithologists' Union, Washington, DC.

Romanoff, A. L., And A. J. RomanofF. 1949. The avian egg. John Wiley \& Sons, New York.

Stutchbury, B. J., AND R. J. Robertson. 1988. Within-season and age-related patterns of reproductive performance in female Tree Swallows (Tachycineta bicolor). Can. J. Zool. 66:827-834.

Weatherhead, P. J., and S. G. Sealy. 1985. Risks of clustering in thermally-stressed swallows. Condor $87: 443-444$.

\title{
A TECHNIQUE FOR DORSAL SUBCUTANEOUS IMPLANTATION OF HEART RATE BIOTELEMETRY TRANSMITTERS IN BLACK DUCKS: APPLICATION IN AN AIRCRAFT NOISE RESPONSE STUDY ${ }^{1}$
}

\author{
Craig A. Harms \\ Department of Microbiology, Pathology and Parasitology, \\ College of Veterinary Medicine, North Carolina State University, Raleigh, NC 27606 \\ W. JAMES Fleming \\ National Biological Service, North Carolina Cooperative Fish and Wildlife Research Unit \\ and Department of Zoology, North Carolina State University, Raleigh, NC 27695 \\ Michael K. StoskopF \\ Department of Companion Animal and Special Species Medicine, \\ College of Veterinary Medicine, North Carolina State University, Raleigh, NC 27606
}

\begin{abstract}
A technique for heart rate biotelemetry transmitter implantation was developed to monitor heart rate fluctuations of Black Ducks (Anas ru-

\footnotetext{
${ }^{1}$ Received 26 April 1996. Accepted 15 October 1996.
}

bripes) in response to simulated aircraft noise in a large outdoor enclosure. A dorsal subcutaneous approach, with subcutaneous tunneling of lead wires, was employed for placement of the $32 \mathrm{~g}$ transmitters. A base-apex lead configuration, with leads anchored at the dorsal cervico-thoracic junction and the caudal keel, yielded the maximal ECG wave-form 
deflection for triggering the transmitter. Heart rates of six Black Ducks (three in each of two separate trials) were monitored for 3 days pre-noise to establish a baseline, and then for 4 days of simulated aircraft noise. The noise stimulus replicated an FB-111 military jet, and was played 48 times per day at a peak volume of $110 \mathrm{~dB}$. Daily mean heart rates, used as indicators of metabolic rates, did not increase in response to noise. Recognizable acute heart rate increases corresponding with a noise event occurred with increased frequency during the first day of noise presentation, but on subsequent days the responses did not differ significantly from baseline. Acute heart rate responses to aircraft noise diminished rapidly, indicating the ability of Black Ducks to habituate to the auditory component of low altitude aircraft overflights.

Key words: Black Duck, Anas rubripes, biotelemetry, heart rate, noise, stress.

The United States Department of Defense controls approximately 25 million acres, much of it prime wilderness harboring some 94 threatened and endangered species (Tennesen 1993). Military procedures exclude some development, with the beneficial byproduct of wildlife habitat preservation. Nevertheless, some hazards to wildlife, including artillery and toxins, are associated with living on military land (Dinkines et al. 1992, Racine et al. 1992).

Extensive areas of North Carolina salt marsh are exposed to low altitude military aircraft training flights. These areas also serve as breeding habitat for Black Ducks (Anas rubripes), which have undergone both range and population contraction (Hindman and Stotts 1989). The effects of military flight training on Black Duck populations are therefore of some concern.

Heart rate is a useful indicator of an animal's physiological status and degree of arousal, and can be used to assess response to disturbances. Heart rate and metabolic rate have been correlated in many species of animals, including Black Ducks (Wooley and Owen 1977), and heart rate can be used as an indicator of energetic costs of animal activity (Wooley and Owen 1978). Caution is necessary in this interpretation however because the relationship between heart rate and metabolic rate breaks down when the animal becomes excited (Wooley and Owen 1977, Chabot et al. 1990). During excitement, heart rate becomes a useful indicator of degree of arousal, increasing in response to disturbances even in the $a b-$ sence of observable behavioral alterations.

Direct measurements of heart rate in wild animals affect heart rate by the addition of stressful stimuli such as the presence of the investigator and physical restraint. Advances in radio telemetry transmitter design have made remote monitoring of physiological parameters possible. Externally mounted transmitters have been used in a variety of birds for location, heart rate, temperature, and respiratory measurements (Gessaman 1978, Kanwisher et al. 1978). These studies have produced useful information, but in some birds the harnesses and percutaneous leads were tolerated poorly (Sawby and Gessaman 1974, Butler and Woakes 1976). Black Ducks markedly reduced feeding time and increased preening time following attachment of external transmitters (Wooley and Owen 1978).

Implantable transmitters avoid many of the drawbacks of external mounting, but because of their reduced size, have smaller ranges, fewer modalities and shorter battery life (Schober and Wagner 1988). Surgical implantation of biotelemetry instruments in wild animals requires anesthesia and invasive surgery, and introduces a space occupying object that can interfere with normal physiology if implant size and location are not chosen carefully. Implantable transmitters have been used to monitor heart rate and respiratory rate in geese and diving ducks (Butler and Woakes 1982) and heart rate in captive raptors (Rushton and Osgood 1993). Longer range implantable location and mortality transmitters have been used to track Canvasback Duck (Aythya valisineria) movements in the Chesapeake Bay (Olsen et al 1992). Biotelemetry transmitters used in birds have generally been placed intraabdominally (Butler and Woakes 1982, Olsen et al. 1992, Rushton and Osgood 1993), and heart rate leads have been embedded intrathoracically (Sawby and Gessaman 1974, Gessaman 1978, Butler and Woakes 1982) or subcutaneously (Rushton and Osgood 1993).

This paper reports a technique for dorsal subcutaneous implantation of heart rate biotelemetry transmitters and explores remote monitoring of heart rate to assess the physiologic impact of aircraft noise on Black Ducks. Heart rate telemetry units were used to monitor heart rate responses of captive wild-strain Black Ducks in a naturalistic enclosure during simulated military aircraft overflights. Undisturbed baseline heart rates and normal variation were established to study instantaneous (reflecting arousal) and sustained (reflecting metabolic rate) changes in response to aircraft noise, and to evaluate heart rate habituation to aircraft noise.

\section{MATERIALS AND METHODS}

Black Duck males weighing from $1.05-1.45 \mathrm{~kg}$ were selected from a captive wild-strain flock. This flock had no known previous exposure to low altitude aircraft overflights. Twenty-five ducks were used. Two nonimplanted ducks were used initially for ECG characterization to help determine optimal lead placement. Seventeen ducks were implanted in pilot studies developing the methodology, and six were used in the data collection phase (three ducks for each of two separate trials).

Experimental facilities were located at the Fish and Wildlife Educational Unit at North Carolina State University. Ducks were enclosed in a $9.4 \times 14 \mathrm{~m}$ pen, with two parallel flow through ponds $1 \mathrm{~m}$ wide $\times 20 \mathrm{~cm}$ deep extending the length of the pen. Grass and earth or coarse gravel served as substrate. The pen was covered by a large mesh net $3 \mathrm{~m}$ high. A $2 \times 3 \times 3.5 \mathrm{~m}$ enclosed trailer adjacent to the area provided an observation blind and housed the telemetry receiving equipment. Birds were acclimated to the pen for seven days prior to surgery, and at least eight days (range 8-24 days) after surgery. 
Implantable VHF heart rate transmitters powered by a $3 \mathrm{~V} 850 \mathrm{mAH}$ lithium battery were purchased from a commercial vendor (VHF-C-1 heart rate transmitter, Mini-Mitter Co., Inc., Sunriver, OR). The transmitters accommodated rates of up to 480 beats per minute (bpm) on a simulator. The transmitters, in a biocompatible coating, weighed $32 \mathrm{~g}$ and measured $9.5 \times 2.4 \times 1.5 \mathrm{~cm}$. A $5-10^{\circ}$ bend in the transmitter conformed to the curve of the duck's back. Two 28 gauge teflon-coated braided stainless-steel lead wires, 10 and $30 \mathrm{~cm}$ long, exited the coating at one end. The lead wires were knotted at the ends and bared for $1 \mathrm{~cm}$ proximal to the knots. The transmitters emitted a pulse at a specific frequency between $150.000-152.000 \mathrm{MHz}$ when the potential electrical difference between leads exceeded a threshold value of $0.7-0.9 \mathrm{mV}$ (threshold varied by rate). Transmitters were designed to have a 150 -day battery life with continuous duty cycle and a $75-100 \mathrm{~m}$ range. Although battery life was adequate, under actual field conditions range was only about $25 \mathrm{~m}$.

Signals were received with a dipole antenna, mounted $3 \mathrm{~m}$ above ground near one end of the enclosure. The antenna was oriented horizontally to achieve more omnidirectional reception and was connected to a receiver (TR-2 receiver, Telonics Inc., Mesa, AZ) via $6 \mathrm{~m}$ of RG-8 coaxial cable. The signal was boosted between the antenna and receiver with a preamplifier (P150 VGD preamplifier, Advanced Receiver Research, Burlington, CT) powered by a $12 \mathrm{~V}, 300 \mathrm{~A}$ battery to increase the range.

Data were acquired by and stored on a personal computer running Datacol 5.0 ${ }^{\mathrm{TM}}$ software (Minimitter Co.). Data acquisition was set for continuous 10 beat averages cycled through all ducks sequentially and repeatedly. Thus, at a heart rate of $150 \mathrm{bpm}$, the program would switch from one duck to the next every 4 seconds, and could cycle through all three birds in just over 12 seconds. Data file sizes for 24-hr acquisitions were 0.9-1.2 MB. Transmitter frequencies were entered into the Datacol software. To accommodate slight frequency fluctuations after implantation that were due to temperature and surrounding tissue effects, the receiver was fine-tuned in increments of 40 $\mathrm{Hz}$ to match the TR-2 receiver pitch with a computer generated pitch. Tuning had to be very precise, as subtle mismatches in transmitter frequency or receiver tuning could result in a "no signal" read-out.

Optimal lead placement was determined by recording electrocardiograms (ECGs) with subcutaneous needle electrodes in multiple positions on anesthetized ducks in sternal recumbency. Proper lead placement was confirmed as they recovered from anesthesia to a standing awake position. A base-apex lead configuration was selected, with the heart base lead wire placed on dorsal midline at the cervico-thoracic junction, and the heart apex lead on ventral midline about $2 \mathrm{~cm}$ cranial to the caudal extent of the keel (Fig. 1). An intrathoracic apex lead placed in two birds did not improve ECG amplitude, so the less invasive subcutaneous technique was used.

Transmitters were cold-sterilized over night in $2 \%$ glutaraldehyde and rinsed with sterile $0.9 \%$ saline prior to implantation. Birds were transported from the pens to the surgical suite in the morning and returned in the evening after full recovery from anesthesia to minimize the time spent isolated in close confinement. Anesthesia was induced and maintained with isoflurane at $1-4 \%$ in $\mathrm{O}_{2}$ delivered by mask from a precision vaporizer. Respirations, ECG, and oxyhemoglobin saturation were monitored.

Three sites were prepared for surgery (a $10 \mathrm{~cm}^{2}$ area over the dorsal cervico-thoracic junction, a 4 $\mathrm{cm}^{2}$ area cranio-ventral to the right scapulo-humeral joint, and a $4 \mathrm{~cm}^{2}$ area overlying the caudal keel) by plucking feathers followed by alternating scrubs of chlorhexidine and sterile saline. Because the birds were returned to the outdoor pens the same day, surface area of surgical sites was minimized so that surrounding feathers could be preened over the bare skin after surgery. Clear plastic avian surgery drapes maintained the sterile surgical field.

With the duck in sternal recumbency, a $3 \mathrm{~cm}$ transverse skin incision was made just caudal to the cervico-thoracic junction (Fig. 1). Subcutaneous tissue was bluntly dissected caudally from the incision, creating a pocket into which the transmitter could be inserted. Particular care had to be exercised in extending the caudal-most segment of the pocket, where the skin was tightly adhered and more delicate. The shorter base lead was anchored to the dorsal spinous ligament between two of the last few cervical vertebrae with 4-0 polydioxanone suture

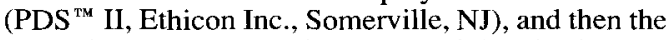
transmitter was inserted. The remaining lead (apex lead) was tunneled subcutaneously in two steps using a stainless steel bitch catheter. It was tunneled first to the right shoulder, then to a position $2 \mathrm{~cm}$ from the caudal extent of the keel, to which it was sutured using 4-0 polydioxanone. Skin incisions were closed with 4-0 polydioxanone suture in a simple continuous pattern.

After the heart rate telemetry unit was implanted, the duck was returned to sternal recumbency, and the receiver retuned to the transmitter in its new environment. Transmitter signals were compared simultaneously to direct ECG readings. Six ducks with good correspondence between ECG and transmitter readings were selected for the noise response study, three ducks in each of two separate trials. Following return to the pen, and prior to initiation of the noise response study, increases in heart rate were evident when a person entered the enclosure with a capture net and walked slowly towards the ducks, demonstrating appropriate transmitter system function. No ducks were subjected to more than two surgeries (implantation and removal), and all were returned to the origination flock at the conclusion of their participation in this study.

Aircraft noise was computer generated, replicating an FB-111 jet flying $70 \mathrm{~m}$ above ground level. Noise was monitored by two Larson-Davis Model 700 noise dosimeters in the pen. The speakers were mounted $2.5 \mathrm{~m}$ off the ground adjacent to the blind. There was no visual component to the aircraft disturbance in these trials. All noise events were $36 \mathrm{sec}$ onds long, with an approach crescendo, a peak at 110 $\mathrm{dB}$ at the center of the pen, and a departing decre- 


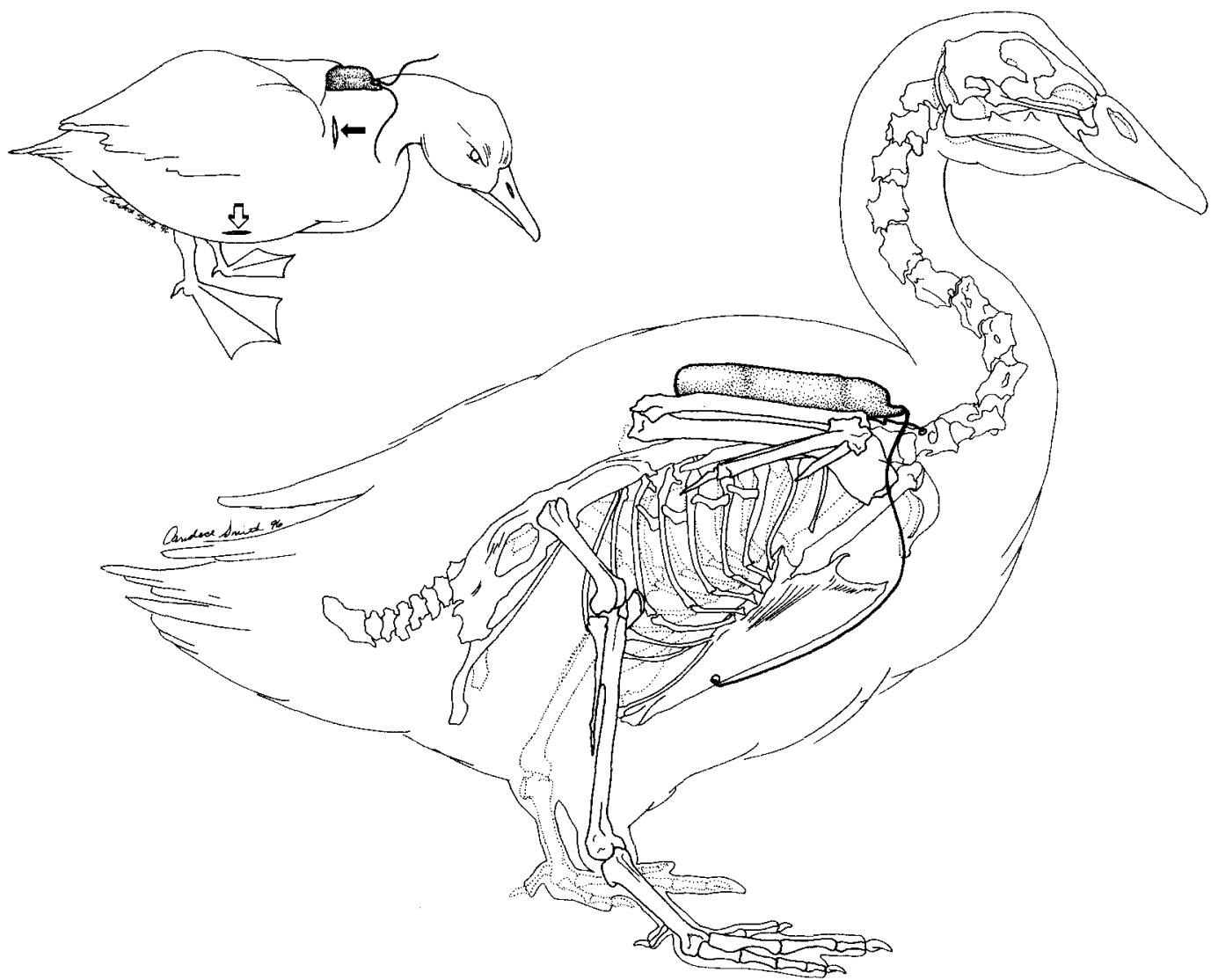

FIGURE 1. Transmitter and lead placement. Transmitter rests subcutaneously over the thoracic spine. Heart base lead is attached to the dorsal spinous ligament of the caudal cervical spine; heart apex lead is attached to the caudal keel. Inset shows location of the three incisions: dorsal cervicothoracic junction, right shoulder (closed arrow), and caudal keel (open arrow).

scendo. Forty-eight noise events occurred each day between $08: 00$ and 24:00, at a rate of three events per hour, randomized within each hour but separated by at least 3 minutes. The event pattern was identical from day to day to allow comparison between days and times. Sound energy and number of events per day were designed to approximate actual military aircraft noise exposures near the center of a military aircraft operating area in coastal North Carolina.

Following the surgery recovery period ( 8 days minimum), baseline heart rate data were acquired for 3 days. Data were then collected for 4 days during noise broadcasts.

Heart rate data for each duck were graphed for 12 hr continuous segments. Hourly means were compared by two-way ANOVA (JMP 3.0.2, SAS Institute Inc., Cary, NC) to detect diel variation. Our only $a$ priori hypothesis concerning hourly means was that there would be some variation, possibly consistent with a diel cycle. Daily means were compared to assess chronic changes in heart rates, which have been correlated with metabolic rates of Black Ducks in a previous study (Wooley and Owen 1977). We hypothesized that noise disturbances would cause increased activity and metabolic rate, which would be reflected in an increased daily mean heart rate. To look at acute responses, data were graphed for 10-min segments spanning $5 \mathrm{~min}$ before and after each of the first six noise events of the day or the equivalent times for the baseline control period. These graphs were evaluated for heart rate increases above background at times corresponding to noise events, and scored 1 for response or 0 for no detectable response. Baseline and noise periods were compared using $2 \times 2$ contingency tables with Yates' correction (Glantz 1992). We hypothesized that detectable heart rate increases in response to noise events would occur more frequently than spontaneous heart rate increases at equivalent times in the absence of noise events, but that this hypothesized response could diminish with time. For all analyses, statistical significance was set at $P<0.05$. Values presented are means $\pm \mathrm{SD}$. 


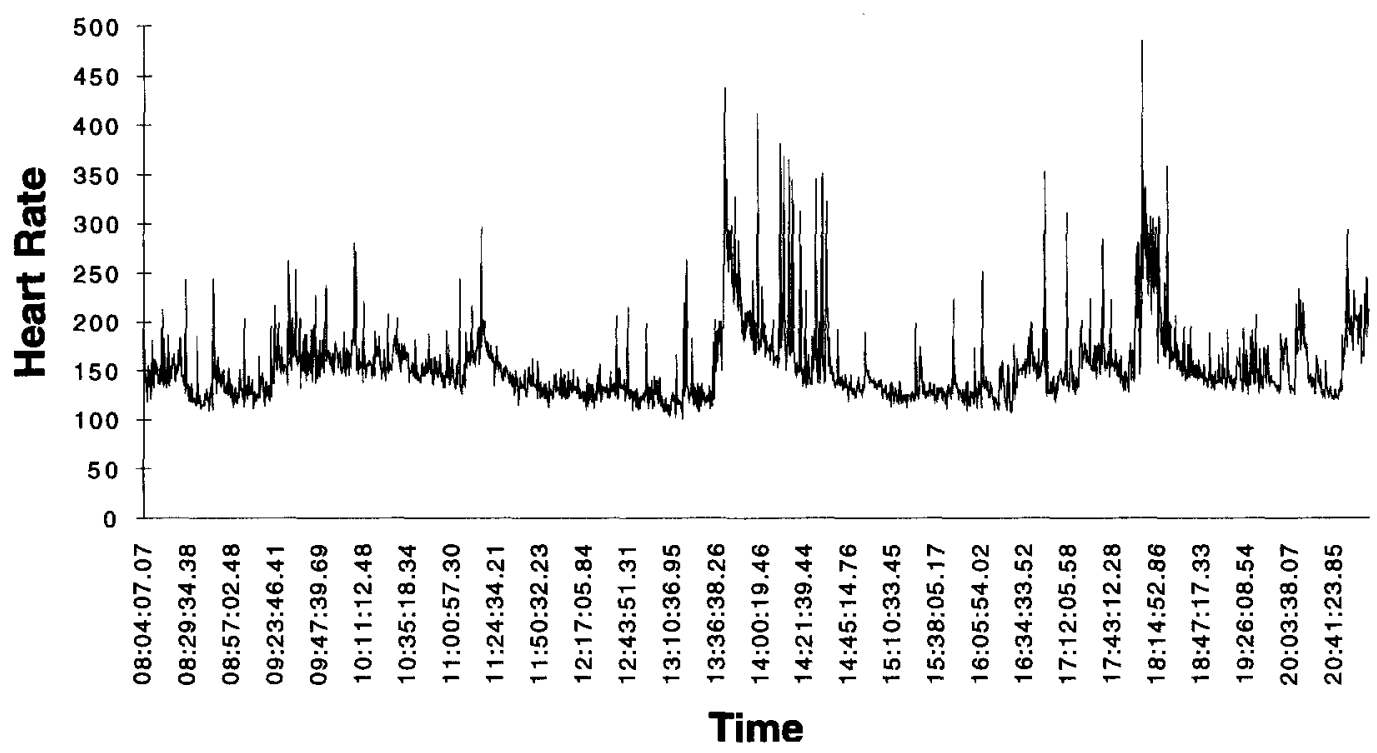

FIGURE 2. Representative individual Black Duck 12-hr, daytime heart-rate profile baseline. The heart rate increase around 18:00 was a consistent finding for all ducks on all days.

\section{RESULTS}

Ducks actively preened initially around surgical sites, but by the day following surgery surrounding feathers were preened over the bare skin and preening behavior returned to normal. Implanted birds could not be distinguished by plumage from nonimplanted ducks without capture. Correspondence between direct ECG readings and transmitted heart rate as measured by the data acquisition program was good in 14 of 23 transmitters. Six of these were used in the noise response study.

Surgical complications included seroma formation ( 2 of 23), dislodged leads (4 of 23), and opening (dehiscence) of suture lines with local infection ( 2 of 23 ), all associated with cranial migration of the transmitter. Seromas and local infections resolved after transmitter removal and lavage with sterile saline. No other surgery-related complications were noted.

Black Duck ECGs were similar to those described for other ducks (Goelz et al. 1990) and other birds (Lumeij and Ritchie 1993), with a mean electrical axis near $-90^{\circ}$, a slurred ST segment, a rapid QRS complex $(0.02 \mathrm{sec})$ and broad $T$ wave. In nearly all ducks tested, the greatest amplitude of the QRS complex $(0.9 \pm 0.27 \mathrm{mV})$ occurred in the base-apex lead configuration. Heart rate under surgical anesthesia averaged $164 \pm 26 \mathrm{bpm}$, and increased to a maximum of $380 \mathrm{bpm}$ during recovery.

A representative baseline 12-hr daytime heart-rate profile from a single duck (Fig. 2), demonstrates the rapid and marked variation in heart rate observed in this study. A consistent finding for all ducks was a sustained increase in heart rate for approximately 30 minutes at dusk. This occurred irrespective of noise broadcasts. Other spikes were observed sporadically both night and day, indicating active periods at all hours. Analyses of variance demonstrated significant differences in hourly heart rate means for each of the ducks $(P<0.01)$. The sources of this variability were not explored further, but patterns for baseline and noise periods were similar. Daily heart rate means exhibited no significant differences attributable to treatment.

Acute responses to noise events were not evident consistently (Fig. 3). When present, heart rate increases in response to noise events were short-lived. A behavioral response often accompanied a heart rate response. Outside disturbances sometimes influenced heart rates when a programmed noise did not. Of interest was one anecdotal observation of a light singleengine plane flying over the flight pen less than 1 min prior to a noise event. The ducks raised their heads and visually tracked the plane, while spiking a brief increase in heart rate, then showed neither behavioral nor heart rate response to the ensuing noise broadcast.

During the 3-day baseline period, spontaneous heart rate spikes occurred 20 of 108 times $(18.5 \%)$ during the first six times corresponding to noise events on subsequent days. On the first day of actual noise the proportion increased to 13 of 35 recorded events $(37.0 \%)(P<0.05)$. On no other individual noise days were proportions significantly greater than baseline, nor was the combined proportion of all noise days, i.e., 37 of 132 recorded events (28.0\%) $(P>0.05)$.

\section{DISCUSSION}

The dorsal subcutaneous implantation site for the transmitter and subcutaneous placement of ECG leads were chosen over abdominal and thoracic locations because the ducks had to be returned directly to their field enclosure following surgery. Because the ducks would be swimming in fecal-contaminated 


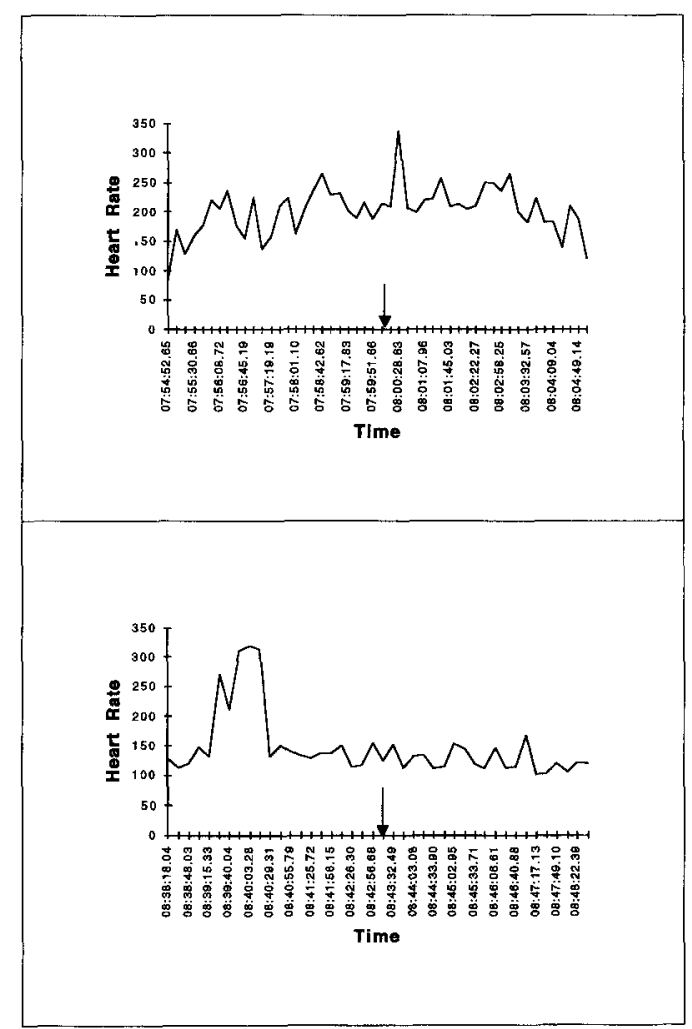

FIGURE 3. Representative individual 10 min heart rate profiles demonstrating response to noise event (upper) and no response to noise event (lower). Arrows indicate start of noise events.

water the day of surgery, a less invasive dorsal subcutaneous implantation, away from water exposure, was preferable to a ventral abdominal incision in direct contact with water. The interscapular area is used typically as a site for subcutaneous fluid therapy in avian patients, and in a $1 \mathrm{~kg}$ duck, this space easily accommodates $40 \mathrm{ml}$ of fluid, a greater volume than the denser $32 \mathrm{~g}$ transmitter. These ducks were in good condition, with adequate subcutaneous fat, which facilitated the dissection of the subcutaneous pocket. Surgical complications could probably have been reduced by suturing the transmitter securely in its subcutaneous position, as seroma formation, dislodged leads and dehiscence were postulated to be related to transmitter mobility.

Changes in transmitter frequency with temperature proved to be a drawback of the dorsal subcutaneous placement of the transmitter. On days when the ducks could bask in direct sunlight, the transmitter temperature increased sufficiently to shift the transmission frequency, resulting first in intermittent signal reception, then gaps in reception until the duck was out of direct sunlight long enough for the transmitter to cool. This resulted in data loss in the middle of some clear days. Normal preening also affected signal quality briefly when preening occurred directly over the leads.

The transmitter met range specifications $(100 \mathrm{~m})$ as close as one meter from the ground, but at ground (and duck) level, range and signal quality were compromised. Radio waves from a transmitter less than 1 wavelength from the ground attenuate, and attenuation increases closer to the ground (American Radio Relay League 1990). Transmitters broadcasting in the $150 \mathrm{MHz}$ range have a wavelength near $2 \mathrm{~m}$. This range problem was ameliorated in this study by adding a pre-amplifier between the receiving antenna and the receiver to boost the incoming signal while filtering frequencies above and below the desired range.

There was no change detected in daily heart rate means attributable to simulated aircraft noise, and hence no evidence of an energetic cost incurred due to noise effects using this measure as an indication of metabolic rate. This study demonstrated acute effects of simulated aircraft noise on heart rates of Black Ducks. The effects were brief and only evident during the first day of noise events. Significant differences disappeared when compared over the entire 4 day course of the noise events. Thus, habituation to frequent loud aircraft noises occurred rapidly.

The rapid habituation to the noise broadcast and the rather mild initial response did not indicate a significant stress response. One possible explanation is the lack of a visual stimulus accompanying the noise. The effect of a light single-engine plane juxtaposed with the subsequent nonresponse to simulated jet noise may derive in part from the visual stimulus. Wooley and Owen (1978) observed certain visual stimuli caused brief increases in Black Duck heart rates, including flying herons and hawks, and lowflying planes. Additional factors in our study may have been the repetition of the identical simulated jet noise on the same (albeit randomized) schedule and from the same position.

Funding for this study was provided by the U.S. Marine Corps Headquarters Office through the Cherry Point Marine Air Station, North Carolina. A computer and digitized sound reproduction equipment were provided by The Noise Effects Branch of Wright-Patterson Air Force Base. The technical assistance of H. Berkhoff, G. Stillman, D. Whitt, P Dennis and K. Beck is gratefully acknowledged. Artwork was performed by Candece Smith. K. Flammer and T. Wolcott graciously reviewed the manuscript.

\section{LITERATURE CITED}

American Radio Relay League. 1990. Antenna fundamentals, 17-1-17-22. In ARRL handbook for the radio amateur, 67th ed. American Radio Relay League, Newington, CT.

Butler, P. J., and A. J. Woakes. 1976. Changes in heart rate and respiratory frequency associated with spontaneous submersion of ducks. Biotelemetry 3:215-218.

Butler, P. J., AND A. J. WOAKES. 1982. Telemetry of physiologic variables from diving and flying birds. Symp. Zool. Soc. Lond. 49:107-128. 
Chabot, D., V. Geist, R. H. Johnston, and R. A. MACARthur. 1990. Heart rate telemetry as a means of investigating duration of disturbance and bioenergetics in free-living ungulates, $p$. 126-131. In R. M. Rangayyan [ed.], Telecommunication for health care: telemetry, teleradiology and telemedicine. Proc. Soc. Photo-op. Instrumentation Eng. 1355, Bellingham, WA.

Dinkines, W. C., R. L. Lochmiller, W. S. Bartush, C. A. DeYoung, C. W. Qualls, Jr., and R. W. Fulton. 1992. Cause-specific mortality of white-tailed deer as influenced by military training activities in southwestern Oklahoma. J. Wildl. Dis. 28:391-399.

Gessaman, J. A. 1978. Body temperature and heart rate of the Snowy Owl. Condor 80:243-245.

Glantz, S. A. 1992. A primer of biostatistics. McGraw-Hill, New York.

Goelz, M. F., A. W. Hahn, and S. T. Kelley. 1990. Effects of halothane and isoflurane on mean arterial blood pressure, heart rate, and respiratory rate in adult Pekin Ducks. Am. J. Vet. Res. $51: 458-460$.

Hindman, L. T., and V. D. Sto'trs. 1989. Chesapeake Bay and North Carolina sounds, p. 27-55. In L. M. Smith, R. L. Pederson, and R. M. Kaminski [eds.], Habitat management for migratory and wintering waterfowl in North America. Texas Tech Univ. Press, Lubbock, TX.

Kanwisher, J. W., T. C. Williams, J. M. Teal, and K. O. LAwSON, JR. 1978. Radiotelemetry of heart rates from free-ranging gulls. Auk 95:288293.

Lumeu, J. T., And B. W. Rirchie. 1993. Cardiology, p. 695-722. In B. W. Ritchie, G. J. Harrison, and L. R. Harrison [eds.], Avian medicine: principles and practice. Wingers Publishing, Lake Worth, FL.

Olsen, G. H., F. J. Dein, G. M. Haramis, and D. G.
JORDE. 1992. Implanting radio transmitters in wintering Canvasbacks. J. Wildl. Manage. 56: 325-328.

Racine, C. H., M. E. Walsh, B. D. RoebucK, C. M. Collins, D. Calkins, L. Reitsma, P. Buchli, and G. GoldFarb. 1992. White phosphorus poisoning of waterfowl in an Alaskan salt marsh. J. Wildl. Dis. 28:669-673.

Rushton, R., And D. W. Osgood. 1993. Physiological monitoring of raptors using an automated biotelemetry system, p. 194-198. In P. T. Redig, J. E. Cooper, D. Remple, and D. B. Hunter [eds.], Raptor biomedicine. Univ. Minnesota Press, Minneapolis, MN.

SAS InstiTUTE. 1994. JMP statistics and graphics guide. Version 3.02. SAS Institute, Inc., Cary, NC.

Sawby, S. W., And J. A. Gessaman. 1974. Telemetry of electrocardiograms from free-living birds: a method of electrode placement. Condor 76:479 481.

SCHOBER, F., AND J. WAGNER. 1988. Considerations on adverse effects of transmitter implants and on limits of surgical feasibility in animal biotelemetry, p. 535-543. In R. M. Rangayyan [ed.], Telecommunication for health care: telemetry, teleradiology and telemedicine. Proc. Soc. Photo-op. Instrumentation Eng. 1355, Bellingham, WA.

Tennesen, M. 1993. Can the military clean up its act? Nat. Wildl. Oct/Nov 1993:14-19.

Wooley, J. B., AND R. B. Owen. 1977 Metabolic rates and heart rate-metabolism relationships in the Black Duck (Anas rubripes). Comp. Biochem. Physiol. 57A: 363-367.

WOOley, J. B., AND R. B. OWEN. 1978. Energy costs of activity and daily energy expenditure in the Black Duck. J. Wildl. Manage. 42:739 745 . 